\title{
Turkish Telemedical Assistance Service: last four years of activity
}

\section{Erkan Çakır, Ömer Arslan}

Dokuz Eylül University Maritime Faculty, Tınaztepe Campus, İzmir, Turkey

\section{ABSTRACT}

Background: Telemedical Assistance Service (TMAS) is very important for seafarers and passengers who are far from full-fledged health services. This study aimed to determine the frequency of using Turkish TMAS by seafarers and other patients and to compare the given services.

Materials and methods: The data obtained from calls to Turkish TMAS in between 2014 and 2017 are composed of 5080 calls. In the study, they were examined in two groups as calls regarding seafarers and other patients. Also, the diseases or injuries related to these calls were evaluated in 22 main groups according to ICD-10 code. All of these cases were analysed by using descriptive statistics according to types of callers, type of diseases, types of given services and methods of contacts.

Results: There were 5080 contacts to Turkish TMAS from January 2014 to December 2017. Contacts were $92.3 \%$ for seafarers and $7.7 \%$ for other patients. The most common reason of contacts was similar for both seafarers and other patients and it was injury and poisoning situations. While the most common service given to seafarers was giving a medicine or other treatment, the most common service given to other patients was medical evacuation.

Conclusions: This study laid weight on diseases or injuries of seafarers and other patients at sea. According to this situation, TMAS can improve and maintain its service quality and also in the light of the findings, a guide for seafarers and other patients can be prepared in order to lessen such diseases and injuries.
\end{abstract}

(Int Marit Health 2018; 69, 3: 184-191)

Key words: telemedicine, maritime health, seafarer, occupational health

\section{INTRODUCTION}

Telemedical services include numerous services and applications all over the world. This kind of service is provided not only for the maritime sector but also for the aviation sector and people on land. Because of this, there is no unique definition of telemedicine. One of the early definitions of telemedicine was published by Bird in 1971, who described it as: "the practice of medicine without the usual physician-patient confrontation. ...via [an] interactive audio-video communications system" [1]. The World Health Organisation (WHO) defines telemedicine as "The delivery of health care services, where distance is a critical factor, by all health care professionals using information and communication technologies for the exchange of valid information for diagnosis, treatment and prevention of disease and injuries, research and evaluation, and for the continuing education of health care providers, all in the interests of advancing the health of individuals and their communities." [2]. Another explanation for telemedicine in the maritime sector was formulated by Saarni and Niemi [3]. In their words, "...telemedicine, which was formerly called Radio Medical, serves medical advice to all ships with the use of telecommunication systems by doctor on land any time, day or night, and also free of charge to all ships" [3]. As understood from all the above definitions, the activity of providing medical care to potential patients such as ship crew, tourists or other travellers on board poses considerable difficulties. The doctor or health care provider cannot see the patient in person owing to the long distance separating them. Because of this, the health care provider 
communicates directly with the patient or the officer who is assigned to provide medical care to the patient by using telecommunication and computer systems. Furthermore, the doctor does not generally have access to the medical history of the patient [4].

The first radio medical service was developed in 1920 in the United States. After that year, several maritime countries, such as Sweden, the Netherlands and Germany, developed radio medical centres for their own fleets. In addition to these developments, the first international organisation for a telemedical service station was established in Italy in $1935[5,9]$. Another international telemedical assistance service station was established in Turkey in 2006, aiming to give free medical advice to all merchant ships, yachts, passenger vessels, fishing boats etc. regardless of their flag or nationality. The Turkish Telemedical Assistance Centre, which is a member of the International Maritime Health Association (IMHA), provides medical advice to both Turkish and foreign air and sea vehicles in all matters and situations related to all kinds of health problems and diseases and performs medical evacuation to ships within the Turkish Search and Rescue Area 24 hours a day, 7 days a week. They also make a medical evacuation arrangement for patients who contact the Turkish Telemedical Assistance Centre from international waters by reaching out to the foreign country's Search and Rescue Coordination Centre when necessary [6].

Any ship, fishing vessel or recreational craft can make direct contact with a health care provider at the Turkish Telemedical Assistance Centre by satellite, cell phone or email in emergency situations related to disease and other health problems. After the first medical evaluation of the patient by a health care provider, the doctor on duty is informed about the patient's situation. In the next step the doctor gives appropriate instructions depending on the severity of the patient's condition, the medicines and medical devices available on board and, if necessary, investigates the patient's medical history and checks the drugs used by the patient. They can also organise the evacuation procedure according to the position of the vessel.

From the start of the Turkish Telemedical Assistance Service Centre's activity on $20^{\text {th }}$ December 2006 until the end of 2017, the Centre assisted with more than 10,000 cases with numerous mails or calls received and transmitted [7]. As shown in Figure 1, the annual number of cases rose dramatically from 292 to 1370 over the years 2007-2017 in parallel to the growing recognition and capacity of the Turkish Telemedical Assistance Service Centre. However, only the last 4 years have been included in this study due to the shortage of data recorded by the Turkish Telemedical Assistance Service (TMAS) in the previous years.

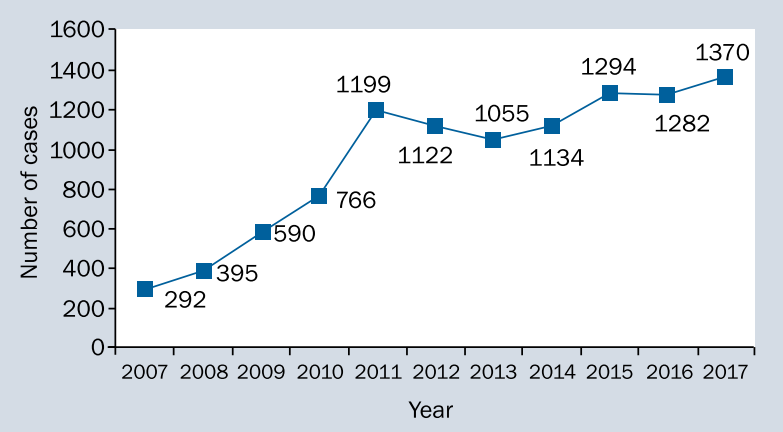

Figure 1. Number of cases assisted by the Turkish Telemedical Assistance Service (TMAS) in the period of 2007-2017 [6, 7]

The aim of this study is to establish internationally comparable data from the Turkish TMAS contacts for patients and to examine medical emergencies arising on merchant ships, fishing vessels, excursion vessels, etc. Such information may be useful for the Turkish TMAS in improving and maintaining service quality and help them be prepared for future requests. It may also serve as a guide for ships to improve safety and health measures in order to reduce medical emergencies on board.

\section{MATERIALS AND METHODS}

The study includes 5080 cases during the 4-year period of 2014-2017, obtained from the Turkish TMAS. These cases included information such as: type of contact, type of ship, nationality of patient, contact position or country, diagnosis and type of evacuation etc. Diseases/injuries and other related information were recorded by doctors at the Turkish TMAS. These diseases/injuries were classified according to World Health Organisation International Classification of Diseases, namely the ICD-10 code [8] by using 3 alphanumeric digits (e.g. 146: Cardiac arrest). In order to make the recorded data more useful and understandable, we converted diseases and injuries into 22 main diagnosis groups already given in the ICD-10 Code (e.g. I00-I99: Diseases of the circulatory system). The cases were examined by dividing patients into two categories: seafarers and other patients, which covered fishermen, passengers, etc. While 4690 contacts were with seafarers, 390 contacts were with other patients. All injury and disease cases were analysed by using descriptive statistics, taking into account the aforementioned two categories. In all the stages of the study, data was gathered taking into consideration ethical standards and without disclosing any personal information.

\section{RESULTS}

Since the year of establishment of the Turkish TMAS, it can be said that the average of 954 cases are handled every year. However, the annual values after 2010 are above this average due to the rise in recognition and capacity of 


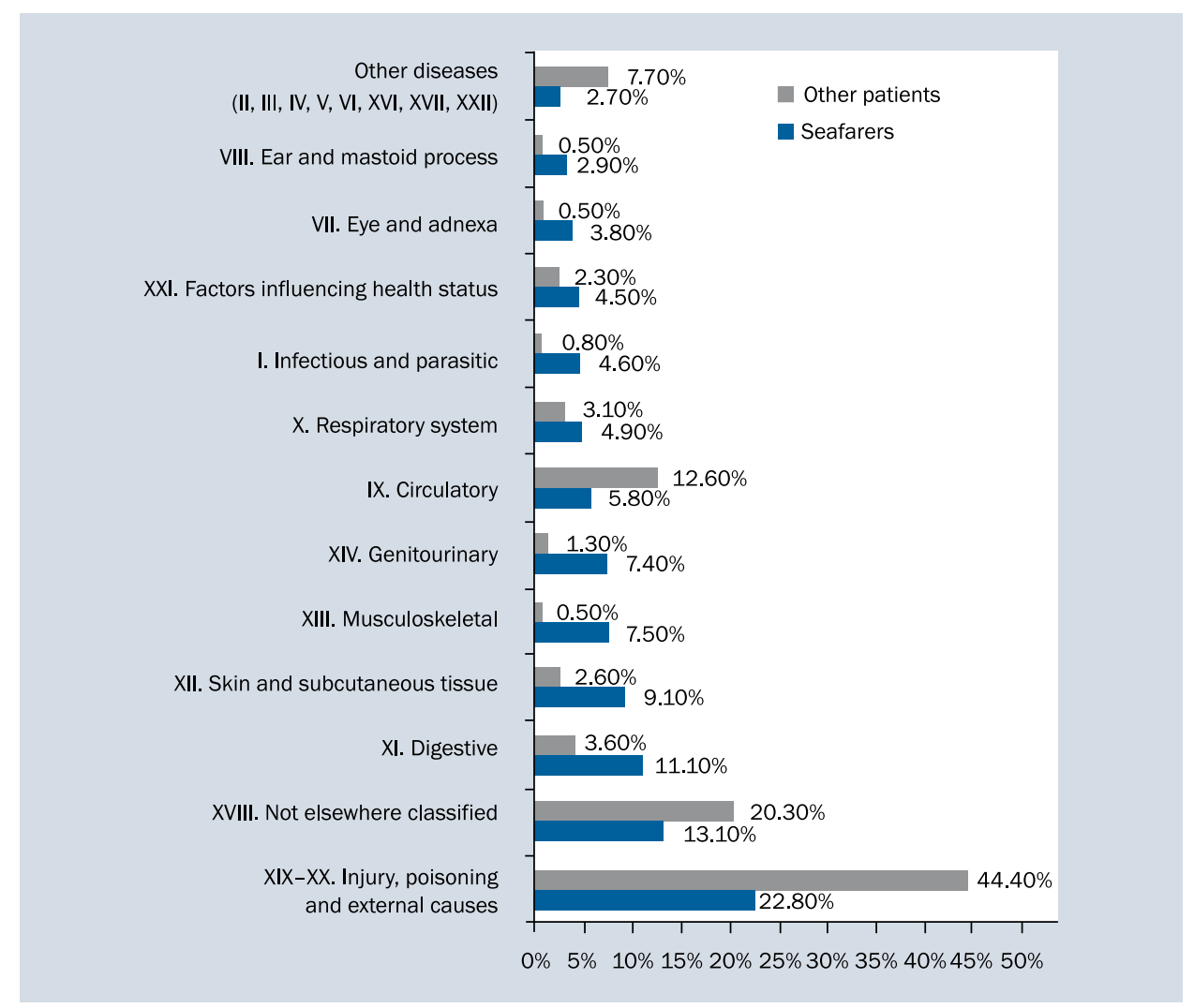

Figure 2. Distribution of the International Classification of Diseases and Related Health Problems (ICD-10) diagnostics for contacts to the Turkish Radio Medical for 4690 seafarers, 390 other patients in the period 2014-2017

the Turkish Telemedical Assistance Centre. Examining the last 4 years, 1134 patients were assisted in 2014, 1294 in 2015, 1282 in 2016 and 1370 in 2017 . Out of the 5080 calls, $78 \%$ were received from foreign and international waters, while $22 \%$ of the calls were received from Turkish coastal waters. Most of the calls (92.3\%) in this period were for seafarers. The ships that contacted the Turkish TMAS for seafarers were generally foreign flagged ships. In other words, $77 \%$ of the merchant ships had flags other than the Turkish flag. However, when the nationalities of seafarers were examined, it was seen that the vast majority (86.2\%) were Turkish. The rest of the contacts were from fishing vessels, yachts and excursion vessels, with $97.4 \%$ of them made from the Turkish coastal waters.

\section{DIAGNOSTIC GROUPS}

Figure 2 shows the main diagnostic groups among 4690 seafarers and 390 other patients according to the International Classification of Diseases and Related Health Problems, $10^{\text {th }}$ revision (ICD-10). The patients among seafarers largely suffered from injury, poisoning and other consequences of external causes (22.8\%), diseases of the digestive system (11.1\%), diseases of skin and subcutaneous tissue (9.1\%), diseases of the musculoskeletal system (7.5\%) and diseases of the genitourinary system (7.4\%). However, 13.1\% of the patients were grouped as "not elsewhere classified" due to insufficient information and less clearly defined symptoms related to cases for establishing a final diagnosis. For other patients, similar to seafarers, the most common reasons of contacts were injury and poisoning situations (44.4\%). However, unlike seafarers, diseases of the circulatory system (12.6\%) and the "other diseases" category including mental and behavioural disorders, diseases of the nervous system, neoplasms, etc. (7.7\%) were some of the main causes of contacts for other patients (Fig. 2).

Figure 3 shows the ten most common specific subgroups in a family of disease, injury and health-related problems recorded by Turkish TMAS doctors using the three-character system according to the ICD-10 code. Dorsalgia (2.9\%), injury by foreign body on external eye (2.7\%), renal colic $(2.5 \%)$, and conjunctivitis (2.0\%) were the most frequent diagnoses which accounted for almost $10 \%$ of the total contacts for seafarers. Calculus of kidney and ureter (1.7\%) and renal colic (2.5\%) were the most common genitourinary system diseases, also accounting for $4.2 \%$ of the total contacts among seafarers. Urticaria (2.0\%) was the most prevalent skin disease which accounted for nearly one fifth of the contacts made for skin disorders. 


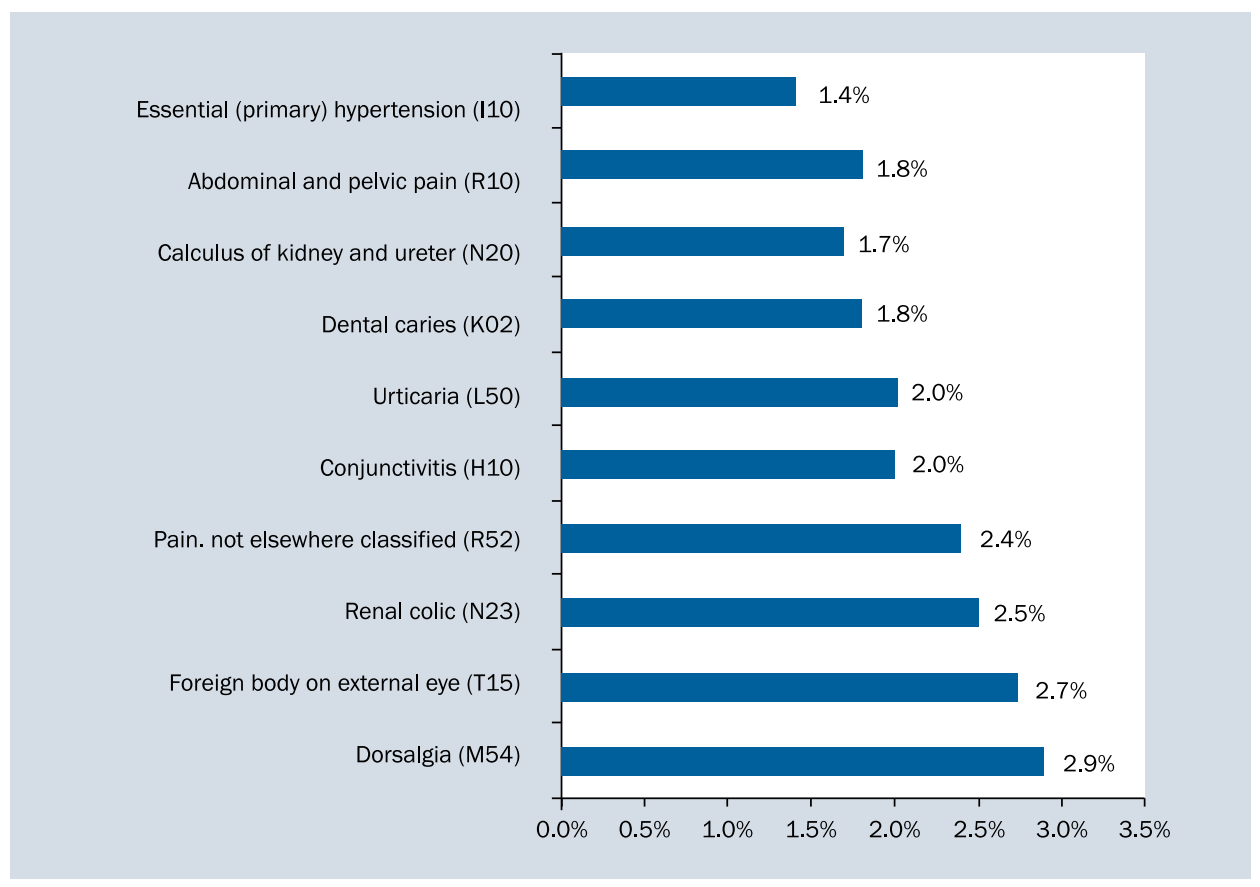

Figure 3. Ten most common diagnoses among seafarers according to contacts to the Turkish Telemedical Assistance Service $(n=4690)$

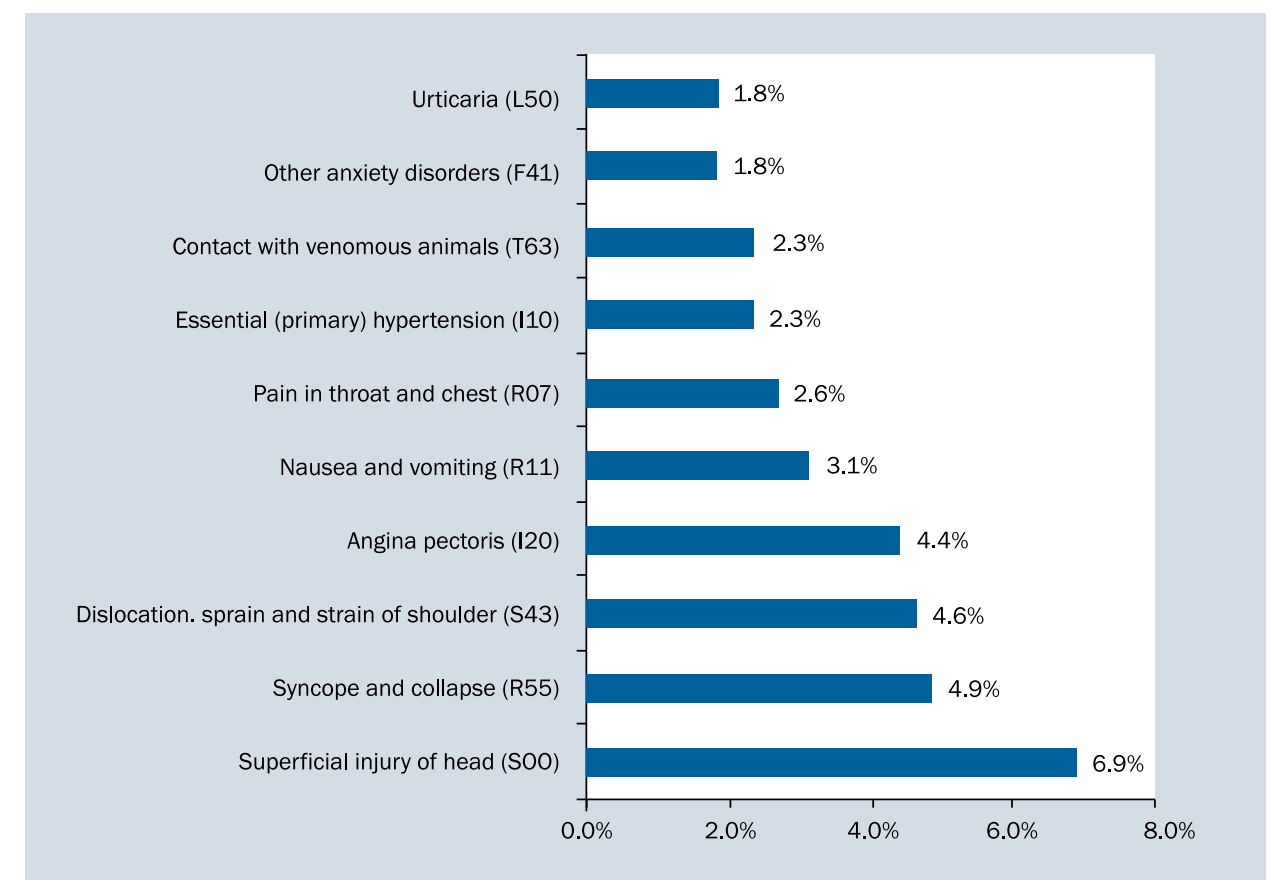

Figure 4. Ten most common diagnoses among other patients according to contacts to the Turkish Telemedical Assistance Service $(n=390)$

For other patients, the most common ten diseases representing one third of the total reasons of contacts are shown in Figure 4. According to this figure, more than $10 \%$ of the contacts were due to superficial injury of the head $(6.9 \%)$ and dislocation, sprain or strain of the shoulder
(4.9\%) which were mostly caused by slipping and falling accidents on excursion vessels, yachts and fishing vessels. Nausea and vomiting (3.1\%) and anxiety disorders (1.8\%), which were among the other reasons of contacts, could be related to seasickness or lack of adaptation to the sea. The 
Table 1. Advice and measures for seafarers and other patients given by the Turkish Radio Medical in the period of 2014-2017

\begin{tabular}{|c|c|c|c|c|c|c|}
\hline \multirow[t]{2}{*}{ Advice and measures } & \multicolumn{2}{|c|}{ Seafarer } & \multicolumn{2}{|c|}{ Other } & \multicolumn{2}{|l|}{ Total } \\
\hline & $\mathbf{N}$ & $\%$ & $\mathbf{N}$ & $\%$ & $\mathbf{N}$ & $\%$ \\
\hline Medicine given or other treatment & 4071 & 86.8 & 58 & 14.9 & 4129 & 81.3 \\
\hline Medical evacuation & 488 & 10.4 & 321 & 82.3 & 809 & 15.9 \\
\hline Advice given only & 116 & 2.5 & 3 & 0.8 & 119 & 2.3 \\
\hline Recommended contact medical clinic next harbour & 15 & 0.3 & 8 & 2.10 & 23 & 0.5 \\
\hline Total & 4690 & 100 & 390 & 100 & 5080 & 100 \\
\hline
\end{tabular}

Table 2. Means of evacuation for seafarers and other patients in the period of 2014-2017

\begin{tabular}{|c|c|c|c|c|c|c|}
\hline \multirow[t]{2}{*}{ Means of evacuation } & \multicolumn{2}{|c|}{ Seafarer } & \multicolumn{2}{|c|}{ Other } & \multicolumn{2}{|c|}{ Total } \\
\hline & $\mathbf{N}$ & $\%$ & $\mathbf{N}$ & $\%$ & $\mathbf{N}$ & $\%$ \\
\hline Coast guard boat & 112 & 23.1 & 241 & 75.1 & 353 & 43.9 \\
\hline Agent boat & 210 & 43.4 & 11 & 3.4 & 221 & 27.5 \\
\hline No information & 21 & 4.3 & 58 & 18.1 & 79 & 9.8 \\
\hline Sea ambulance & 63 & 13 & 6 & 1.9 & 69 & 8.6 \\
\hline Foreign country evacuation & 60 & 12.4 & 0 & 0 & 60 & 7.5 \\
\hline Helicopter & 10 & 2.1 & 4 & 1.2 & 14 & 1.7 \\
\hline Pratique boat & 8 & 2.1 & 1 & 0.4 & 9 & 1.1 \\
\hline Total & 484 & 100 & 321 & 100 & 805 & 100 \\
\hline
\end{tabular}

other most common symptoms among other patients were syncope and collapse, hypertension, angina pectoris and pain in throat and chest (Fig. 4).

\section{GIVEN SERVICE AND MEANS OF EVACUATION}

According to Table 1, out of the 5080 cases, 4129 $(81.3 \%)$ cases were given treatment on board such as tourniquet or wound-packing for injuries, medical prescriptions, checks of blood pressure, temperature and heart rate and continuous monitoring of the patient. A total of 809 medical evacuations (15.9\%) were carried out, 488 for seafarers and 321 for other patients. While 484 medical evacuations represented $10.4 \%$ of the total contacts for seafarers, 321 cases represented $82.3 \%$ of the total contacts for other patients. Precautionary and preventive recommendations were given in 116 (2.5\%) cases regarding the risks of tropical or infectious diseases in the regions to which the vessels would voyage.

When looking at the types of evacuation, coast guard boat and agent boat were used in $71.4 \%$ of the total evacuation cases. While almost half of the evacuations among seafarers were by agent boat, three fourths of the evacuations among other patients were by coast guard boat (Table 2). There were 60 evacuation cases for seafarers conducted in foreign waters by working in collaboration with the Maritime Rescue Coordination Centres (MRCC) of the various countries of the world (Table 2).

\section{COMMUNICATION}

Transmitting or receiving medical information for the patient was conducted using email or telephone. However, in rare cases, fax was used for contacting the Turkish TMAS. These contacts were often made using more than one method, which was usually the telephone and email. Also, in some cases, more than one contact was established in order to monitor and re-evaluate the condition of the patient.

\section{DISCUSSION}

This study examines injuries and illness, given advice and measures and types of evacuation for patients by dividing them into two groups: seafarers and other patients. In this sense, the study includes 4690 contacts with the Turkish TMAS for seafarers from merchant ships and 390 contacts for other patients from fishing vessels, yachts, excursion vessels, etc. Despite the small number of contacts for other patients, the comparison was made for the purpose of revealing differences between these two groups. In order to give a clearer and more comparable picture of injuries and illnesses of patients, the main diagnostic groups were used 
on the basis of the International Statistical Classification of Diseases and Related Health Problems ( $10^{\text {th }}$ revision) of the WHO [8]. This also allowed for a comparison of the study's findings with similar studies [9-14]. However, the ten most common specific diagnoses and subgroups of diseases were given for both seafarers and other patients to draw attention to certain diseases and injuries (Figs. 3, 4).

In this study, injuries and work-related accidents accounted for a significant number of cases both for seafarers (22.8\%) and other patients (44.4\%) and differed substantially in terms of injured body parts for these two groups. While eye injuries (e.g. foreign body on external eye) were one of the most common injury types among seafarers, they were very rare, with a few cases, among other patients. Similarly, Lefkowitz et al. [15] and Napoleone [16] found that eye injuries accounted respectively for $9.5 \%$ and $8 \%$ of total injuries among seafarers, while Westlund et al. [10] revealed that for passengers none of the reported eye problems were due to accident. According to contacts with the Turkish TMAS, eye injuries mostly occurred while fulfilling routine jobs such as welding, painting or working with hazardous chemicals on board merchant ships and they can be considerably reduced by wearing appropriate personal equipment for eye protection. On the other hand, head and shoulder injuries caused by falling and slipping on board excursion vessels and yachts accounted for more than one third of the total injuries among other patients. These findings are consistent with other limited studies investigating diseases and injuries of seafarers and other patients according to contacts with the TMAS. Westlund et al. [10], in a study of 1905 contacts from merchant ships for seafarers and 651 contacts from Swedish ferries for passenger patients, found that the proportion of injuries and work related accidents were on average 20\% for seafarers and $25 \%$ for passengers. Another study on injury and illness of seafarers, including 3921 cases found that $29.5 \%$ of the contacts made to the TMAS were due to work-related injuries [15].

Among the diseases of seafarers, the most prevalent were disorders of the digestive system followed by skin and subcutaneous tissue problems, disorders of the genitourinary system, the musculoskeletal system and circulatory system. These diseases approximately accounted for $40 \%$ of the total number of contacts for seafarers. Unlike seafarers, the majority of the contacts with the Turkish TMAS for other patients were due to acute health problems and diseases such as diseases of circulatory system (e.g. angina pectoris), acute diseases (nausea and vomiting, syncope and collapse, pain in throat and chest, etc.), which are in the "not elsewhere classified" diagnostic group, and acute conditions (contact with marine animal, anxiety disorders, etc.) included in the "other" diagnostic group.
According to our data, illnesses of the digestive system (11.1) such as colitis, gastritis, ulcers and dental problems were the most common causes of contacts among seafarers. Dental illnesses in particular (e.g. dental caries) accounted for nearly $40 \%$ of the diseases of the digestive system among seafarers. Similarly to our findings, a study of diseases in Japanese seafarers [17], including 19,098 cases reported from merchant vessels showed that diseases of the digestive system accounted for $33.5 \%$ of the total diseases. Another study on diseases of seafarers revealed that from the period of 1952-1984 onwards, disorders in the digestive system have been the number one cause of referral to the International Radio Medical Centre (CIRM) [9]. Also, Lefkowitz et al. [15] observed that dental problems were the second most frequently prompted request for assistance among contacts for seafarers. As can be understood from the studies mentioned above, diseases of the digestive system are the most common diseases among seafarers today, like they were in the past. These diseases might be related to bad eating habits, excessive alcohol consumption and smoking and also being deprived of regular dental care due to long voyages, which increases the risk of dental problems for seafarers. The diseases of the digestive system could be decreased by improving food and water quality on board ships and by developing more effective alcohol consumption reduction policies. In addition, providing better oral hygiene education for seafarers [18] and performing detailed dental examinations before embarking on a ship could help reduce dental complaints.

Our data showed that skin disorders were the second-most prevalent cause of consultations among seafarers and accounted for $9.1 \%$ of the total contacts. This is consistent with other prior studies which were based on telemedical data. Lefkowitz et al. [15] and Lucas et al. [19] found that $10 \%$ of the calls were due to skin disorders. Similarly, McKay [14], in his study of 866 cases on commercial ships flying the United States flag, revealed that non-traumatic skin lesions such as rashes and cellulitis accounted for $8 \%$ of the medical cases. Also, according to a study by Lucas et al. [19], $68 \%$ of the skin disorders were infectious and cutaneous abscesses and cellulitis, which were the most frequent skin disorders encountered. In contrast to this situation, in our study, urticaria alone accounted for almost $20 \%$ of the total skin disorders while infectious skin disorders accounted for $30 \%$ of them. At the present time, skin diseases could be better diagnosed and treated by means of attaching digital images related to the case to e-mail messages sent for consultation. This could prevent the recurrence of skin disorders and lead to a decrease in contacts to TMAS for such complaints.

In the present study, 4129 (81.3\%) of the 5080 cases were given a medical prescription or other treatment 
on board and 809 (15.9\%) cases were evacuated to a medical facility by means of coast guard boat, agent boat, helicopter, etc. This is fairly similar to results from another study which found that $12.3 \%$ of total cases resulted in medical evacuation [13]. In contrast, a study comprising 9071 contacts to the CIRM found that evacuations were inevitable in approximately $3.5 \%$ of the cases in 2010 and 2011 and $2.2 \%$ of the cases in 2012 [20]. Also, our data showed that almost $11 \%$ of the calls from merchant vessels for seafarers resulted in an evacuation, while out of the calls from fishing vessels, yachts, excursion vessels and passenger vessels for other patients $82.3 \%$ resulted in an evacuation. Similarly, Westlund et al. [10] found that the proportion of evacuations was almost three times higher for passengers than for seafarers. Another study by Mitchelson et al. [21] found that approximately $85 \%$ of calls from fishing vessels resulted in an evacuation. This significant difference in evacuation rate between seafarers and other patients is probably due to the fact that contacts for seafarers were largely from international waters and foreign countries, while almost all of the contacts for other patients were from coastal waters. Also the higher evacuation rate among other patients could be explained by the fact that traumatic and acute cases were widely prevalent among other patients. In addition to that, Westlund et al. [10] stated that the difference in the proportion of evacuations between seafarers and passengers probably arises from the fact that seafarers have to undergo a medical examination every 2 years, which makes them a group selected from among healthy population while the passenger group is composed of older individuals with no obligatory medical examination before embarking on a ship. However, further studies should be carried out to evaluate the effect of the patient's age, type of injury/illness, vessel type etc. on the decision of evacuation in order take measures and develop strategies for reducing the evacuation ratio among both seafarers and other patients.

\section{CONCLUSIONS}

In conclusion, it was found that there were significant differences between seafarers and other patients in terms of diseases, medical evacuation ratio and means of evacuation. For both seafarers and other patients, injuries and work related accidents were the most prevalent causes of contact. However, digestive system disorders were found to be the most common disease type among seafarers, while circulatory system disorders were the most frequent diseases among other patients. The evacuation ratio was eight times higher among other patients than among seafarers, and a coast guard boat was the most commonly used mean of evacuation for other patients while an agent boat was mostly used for the evacuation of seafarers.
The Turkish TMAS has been contacted for many different types of injuries and illnesses since it was founded. This fact may contribute to the development of telemedical services by sharing these cases and information at international meetings. Furthermore, establishing a common international database and enhancing information sharing between telemedical service organisations may increase the likelihood of diagnostic success and could be used to elucidate the risk factors for medical emergencies in order to take preventive measures aimed at reducing such emergencies on board.

\section{REFERENCES}

1. Bird KT. Teleconsultation: A New Health Information Exchange System. Third Annu. Rep. Veterans Admin. Washington, DC. 1971.

2. World Health Organization. A Health Telematics Policy: Report of WHO Group Consultation on Health Telematics. 1998.

3. Saarni H, Niemi L. Medical Handbook for Seafarers. Finnish Institute of Occupational Health, Helsinki. 2007.

4. Angioli RD, Saturnino A, Sibilio F, Amenta F. Healthy Ship: A New Project for Improving Medical Care of Sailing Seafarers. http://www. cirm.it/documenti/cirm_th3-2.pdf.

5. Goethe WHG, Watson EN. and Jones DT (eds.). Handbook of NauticalMedicine. Springer-Verlag Berlin, Heidelberg. 1984.

6. http://www.telesaglik.gov.tr/ (Accessed: 12/03/2018)).

7. http://www.telesaglik.gov.tr/category/istatistikler/ (Accessed: 12/03/2018).

8. World Health Organization. International Statistical Classification of Diseases and Related Health Problems 10th Revision. WHO, Geneva. 2011.

9. Mahdi SS, Amenta F. Eighty years of CIRM. A journey of commitment and dedication in providing maritime medical assistance. Int Marit Health. 2016; 67(4): 187-195, doi: 10.5603/IMH.2016.0036, indexed in Pubmed: 28009394.

10. Westlund K, Attvall S, Nilsson R, et al. Telemedical Maritime Assistance Service (TMAS) to Swedish merchant and passengers ships 1997-2012. Int Marit Health. 2016; 67(1): 24-30, doi: 10.5603/ IMH.2016.0006, indexed in Pubmed: 27029926.

11. Amenta F, Dauri A. Activities of the International Radio Medical Centre (C.I.R.M.) in Rome during the last five years (1996-2000). Centro Internazionale Radio Medico. Int Marit Health. 2001; 52(1-4): 68-73, indexed in Pubmed: 11817843.

12. Amenta F, Dauri A, Rizzo N. Organization and activities of the International Radio Medical Centre (CIRM). J Telemed Telecare. 1996; 2(3): 125-131, doi: 10.1258/1357633961929907, indexed in Pubmed: 9375045.

13. Lateef F, Anantharaman V. Maritime radio-medical services: the Singapore General Hospital experience. Am J Emerg Med. 2002; 20(4): 349-351, indexed in Pubmed: 12098185.

14. McKay MP. Maritime health emergencies. Occup Med (Lond). 2007; 57(6): 453-455, doi: 10.1093/occmed/kqm053, indexed in Pubmed: 17652345.

15. Lefkowitz RY, Slade MD, Redlich CA. "Injury, illness, and work restriction in merchant seafarers”. Am J Ind Med. 2015; 58(6): 688-696, doi: 10.1002/ajim.22459, indexed in Pubmed: 25939921.

16. Napoleone P. Accidents on board merchant ships. Suggestions based on Centro Internazionale Radio Medico (CIRM) experience. Int Marit Health. 2016; 67(1): 21-23, doi: 10.5603/IMH.2016.0005, indexed in Pubmed: 27029925. 
17. Ehara M, Muramatsu S, Sano Y, et al. The tendency of diseases among seamen during the last fifteen years in Japan. Ind Health. 2006; 44(1): 155-160, indexed in Pubmed: 16610553.

18. Mahdi SS, Sibilio F, Amenta F. Dental hygiene habits and oral health status of seafarers. Int Marit Health. 2016; 67(1): 9-13, doi: 10.5603/IMH.2016.0003, indexed in Pubmed: 27029923.

19. Lucas R, Boniface K, Hite M. Skin disorders at sea. Int Marit Health. 2010; 61: 9-12.
20. Amenta F, Capone L, Sibilio F. (2013). Telemedical assistance of patients on board ships activity of Centro Internazionale Radio Medico (CIRM), the Italian Telemedical Maritime Assistance Service (TMAS). http://www.cirm.it/documenti/cirm_th3-1.pdf.

21. Mitchelson MA, Ferguson J, Armes R, et al. Characteristics of radio medical advice to fishing vessels in Scottish coastal waters. J Telemed Telecare. 2008; 14(3): 145-146, doi: 10.1258/ jtt.2008.003014, indexed in Pubmed: 18430284. 